\title{
Influence of mechanical impurities on the risk of failure power transformer and possible ways reduce it
}

\author{
Olga Melnikova ${ }^{1, *}$ Vitaliy Savelyev ${ }^{1}$ and Vera Bataeva $^{1}$ \\ ${ }^{1}$ Ivanovo State Power Engineering University, 34 Rabfakovskaya st, Ivanovo, Russia
}

\begin{abstract}
The report presents the results of evaluating the effect of mechanical impurities on the electrical strength of transformer oil and discusses ways to reduce the risk of power transformer failures due to this factor.
\end{abstract}

\section{Introduction}

In order to extend the service life and reduce the risk of failures of power transformers in operation, the issue of improving methods for diagnosing the isolation of power transformers and regulatory and technical documentation $[1,2,3]$, which was developed decades ago, becomes relevant. Regulatory indicators of the Russian Federation differ from those recommended by international organizations CIGRE and IEC in the direction of reducing the quality of insulation. In addition, the improvement of insulation diagnostics meets resistance from energy companies, as this will be accompanied by additional operating costs.

During the operation of power transformers, the electrical insulation strength decreases [4]. This damage is caused by the design features of power transformers, which are insulated with an oil barrier type and represent an alternation of barriers from electrical cardboard and oil channels. The criterion for breaking the electrical strength of the oil barrier insulation is the breakdown of oil channels, which leads to irreversible consequences of the transformer operation as a whole [5, 6].

Therefore, one of the important parameters in the diagnosis of insulation of power transformers is considered to be the electrical strength of transformers, and the electrical strength of transformer oil is considered. In accordance with [7], the average value of the breakdown voltage is the first parameter for testing transformer oil. In accordance with [8], the coefficient of variation of passive stresses relative to the average value is also determined

$$
V=\frac{\sigma_{u} \cdot 100}{\langle U>}
$$

where $\sigma_{u}$ is the mean square error of the arithmetic mean value of the breakdown voltage (mean square deviation); $<U>$ is the arithmetic mean of the breakdown voltage.

However, this indicator is not reflected in [7]. The coefficient of variation in accordance with [8] is determined for any electrical fluids, and its standard values should not exceed $20 \%$, while for technically pure transformer oil, this coefficient is $10-15 \%$ [4]. In accordance with the American standard [9], which provides for the determination of breakdown stresses only for petroleum oils, this coefficient is $6 \%$ [10].

The mechanism of breakdown of transformer oil is statistical in nature, and if the coefficient of variation has values exceeding $10-15 \%$, this indicates the presence of mechanical impurities in the transformer oil [11]. The electrical strength of the oil is affected by both the distribution and particle size, and the conductivity of impurities is important. Mechanical particles under the action of a strong field form bridges that contribute to the passage of oil insulation channels. The presence of particles, bridges, and separate chains leads to the formation of partial discharges and further damage to the cellulose insulation of power transformers [12]. The most common mechanical impurity particles are moistened fibers and graphite (carbon). Fibers in transformer oil appear due to the separation of particles from solid barriers made of electrical cardboard at the manufacturing stages, as well as in the operation of transformers during continuous oil circulation and during insulation aging. If the liquid is heavily contaminated with solid particles, the formation of discharges occurs relatively quickly. It is rather difficult to assess the influence of impurities on the electrical strength of oil and insulation in General experimentally [12].

Currently, the Russian Federation has adopted a standard for operational transformer oils in accordance with [7] [13], which provides for the determination of liquid purity classes from the number of pollutant particles in $100 \mathrm{~cm} 3$. Taking into account the voltage classes to ensure a given level of electrical insulation strength, the standard values of the liquid purity classes are set accordingly for equipment with a voltage of up to $220 \mathrm{kV}$ - class 13 , for equipment with a voltage of $220 \mathrm{kV}$ to $750 \mathrm{kV}$ - class 12 . As the voltage class increases, the requirements for oil quality for the presence of mechanical impurities are tightened, while the number of the liquid purity class decreases. It should be noted that according to the recommendation of SIGRE, to ensure high strength of transformer oil for operation, class 9 of liquid purity is provided [4, 14].

Taking into account the above, the research sets and solves the problems of determining the distribution of

* Corresponding author: o.c.melnikova@mail.ru 
impurity particles by size, taking into account the purity classes of the liquid, and also considers the effect on the electrical strength of transformer oil of the presence of dry and moistened fibers, graphite (carbon), metal particles depending on their size, quantity, conductivity and position relative to the electrodes.

\section{Research methods}

Studies of the influence of particles of mechanical impurities were carried out using a standard test cell for determining the breakdown voltage according to [8].
A physical model of a standard cell for calculating the effect of impurity particles on the electrical strength of oil was performed in the ANSYS Maxwell software package. In the considered model, the boundary conditions were set in the form of a cube with the electrode system Fig. 1. all elements of the physical model were given electrical characteristics of the corresponding materials (table 1). The Electrodes are made of copper, the test cell is filled with transformer oil, the most commonly used brand of transformer oil in electrical equipment of higher voltage classes is GC. The distance between the system electrodes $\mathrm{d}=2.5 \mathrm{~mm}$.

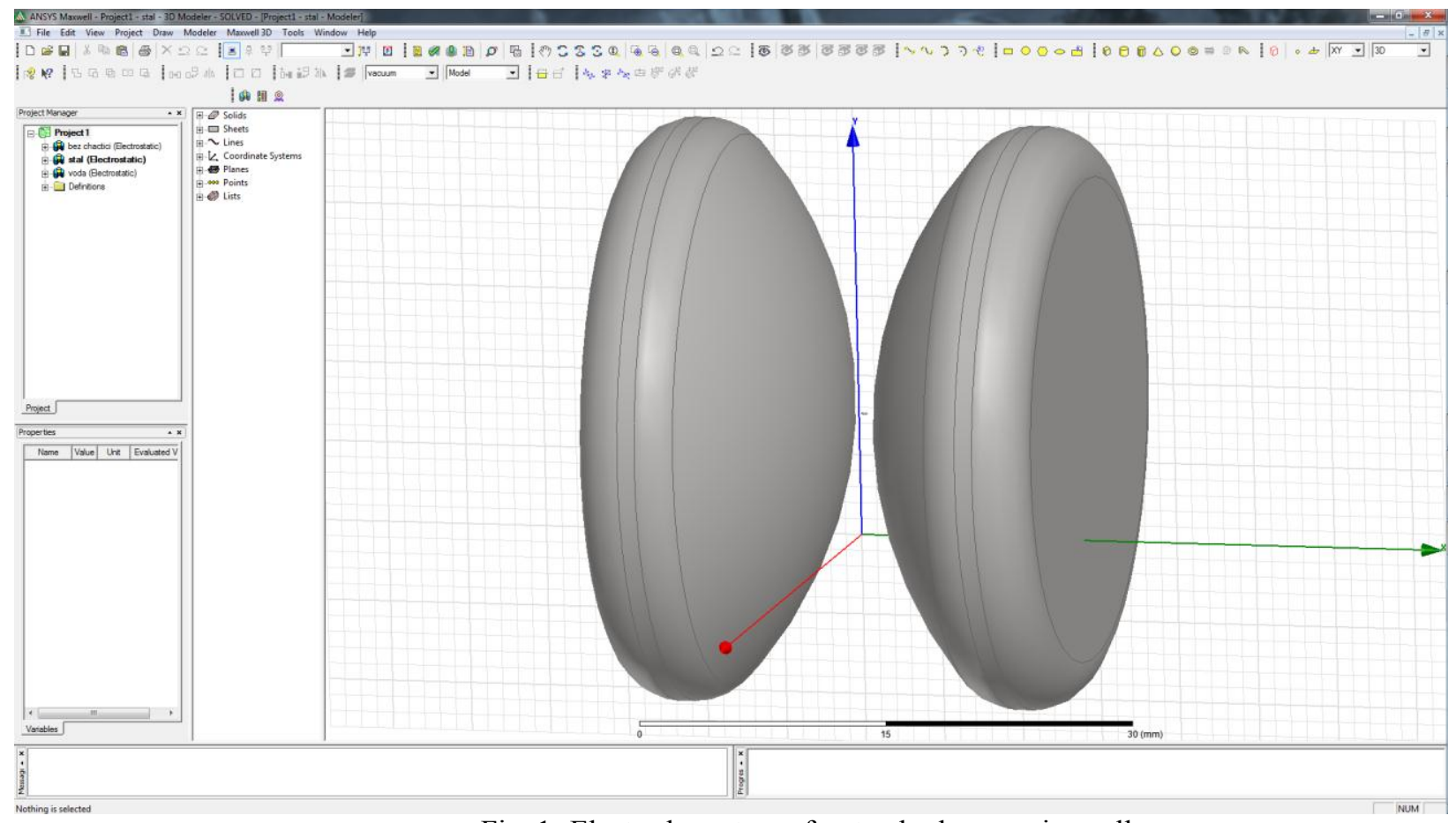

Fig. 1- Electrode system of a standard measuring cell in the ANSYS Maxwell

Table 1. Electrophysical characteristics of simulated transformer oil and particles

\begin{tabular}{|l|c|c|}
\hline \multirow{2}{*}{ Materials } & \multicolumn{2}{|c|}{$\begin{array}{c}\text { Electrophysical } \\
\text { characteristics }\end{array}$} \\
\cline { 2 - 4 } & $\begin{array}{c}\text { relative } \\
\text { dielectric } \\
\text { constant } \\
\varepsilon_{\mathrm{r}}\end{array}$ & $\begin{array}{c}\text { Specific } \\
\text { resistance } \\
\rho, \text { OM M }\end{array}$ \\
\hline $\begin{array}{l}\text { Transformer oil (GC) } \\
\text { fibers } \\
\text { Cellulose fibers } \\
\text { (cardboard for main } \\
\text { insulation grade A) at } \\
\mathrm{c}_{\mathrm{w}}=1 \% \text { main }\end{array}$ & 4 & $10^{12}$ \\
\hline $\begin{array}{l}\text { Cellulose } \\
\text { (cardboard for } \\
\text { insulation grade A) at } \\
\mathrm{c}_{\mathrm{w}}=6 \%\end{array}$ & 12 & $10^{12}$ \\
\hline Graphite (carbon) & $10-15$ & $10^{-6}-10^{-4}$ \\
\hline Iron & - & $10^{-6}-10^{-4}$ \\
\hline
\end{tabular}

Various particles were placed between the system's electrodes. A voltage of $40 \mathrm{kV}$ was applied to one of the electrodes, and the second electrode was grounded. The value of $40 \mathrm{kV}$ is the average breakdown voltage in a standard cell for operating oil of equipment with a class up to $150 \mathrm{kV}$ in accordance with [7].

The following are the results of modeling in the ANSYS Maxwell environment. They are presented in the form of field pictures and graphs of the electric field strength along the axis of the electrode system. These data clearly reflect the influence of impurity particles and allow us to accurately estimate the values of the electric field strength at any point in the system.

To get a complete picture of the effect of impurity particles on the electric field, the voltage in the gap between the electrodes without particles was estimated (Fig. 2).

In order to verify the reliability of the results obtained, it is necessary to calculate the maximum permissible average value of the voltage in a system with a uniform electric field. Then

$$
E=\frac{U}{d}=\frac{40}{2,5}=16 \mathrm{\kappa V} / \mathrm{mm} .
$$


The results obtained during measurements and modeling are the same. It is also necessary to calculate the maximum values of breakdown voltages for pure transformer oil. Pure transformer oil can have a breakdown voltage of up to $80 \mathrm{kV}$. Thus, its breakdown strength when recalculated by (2)

$$
E_{\max }=\frac{U}{d}=\frac{80}{2,5}=32 \mathrm{kV} / \mathrm{mm} .
$$

Therefore, the appearance of at least one particle will strongly affect the electrical strength of the oil and if the Emax is exceeded in the interval, the insulation will break even at a lower voltage.

To assess the effect of cellulose fibers, particles were considered at a water concentration of $\mathrm{Cw}=1 \%$ (dry fibers) and $\mathrm{Cw}=6 \%$ (moistened fibers), and the length of the fibers varied from 100 microns to 400 microns in accordance with $[13,14]$.

\section{Research result}

Figure 3 shows that in the presence of a wet fiber, the electric field becomes sharply inhomogeneous, and the maximum intensity is observed at the interface between the liquid dielectric and the particle.

From the analysis of the simulation results obtained, it follows that dry fibers have a weak effect on the distortion of the electric field strength (Fig. 4). For wet fibers longer than 200 microns, a decrease in the growth rate of the electric field strength is observed. Wetting the fibers 6 times (from $1 \%$ to $6 \%$ ) leads to an increase in the electric field strength at their ends. Thus, the maximum increase in tension in $100-$ micron fibers reaches $32.4 \%$, in $200-\mathrm{mm}$ fibers $-84.46 \%$, and in 400 - $\mathrm{mm}$ fibers $111 \%$. From the results obtained, it follows that with a slight increase in the electric field strength, the electrical strength of pure transformer oil will be violated, and it can also be noted that the maximum values of tension exceeding the value of $32 \mathrm{kV} / \mathrm{mm}$ correspond to one particle of a moistened fiber 200 microns long or more.

The values of the maximum electric field strengths at the location of the bridge consisting of dry and moistened fibers between the system electrodes are shown in Fig. 5.

It should be noted that the field strength in bridges made of dry fibers (from 100 to 500 microns) does not exceed the electrical strength of pure transformer oil in 32 $\mathrm{kV} / \mathrm{mm}$. For bridges made of wet fibers, the field strength begins to exceed the electrical strength of pure oil when the fiber length is more than 200 microns. An increase in the field strength between the fibers, especially in the wet state, above the electrical strength of pure transformer oil, leads to an increase in ionization processes in the oil layers and a decrease in the electrical strength of the entire oil gap. Thus, we can conclude that the greatest influence on the reduction of the electrical strength of oil gaps is exerted by moistened fibers with a length of more than 200 microns.

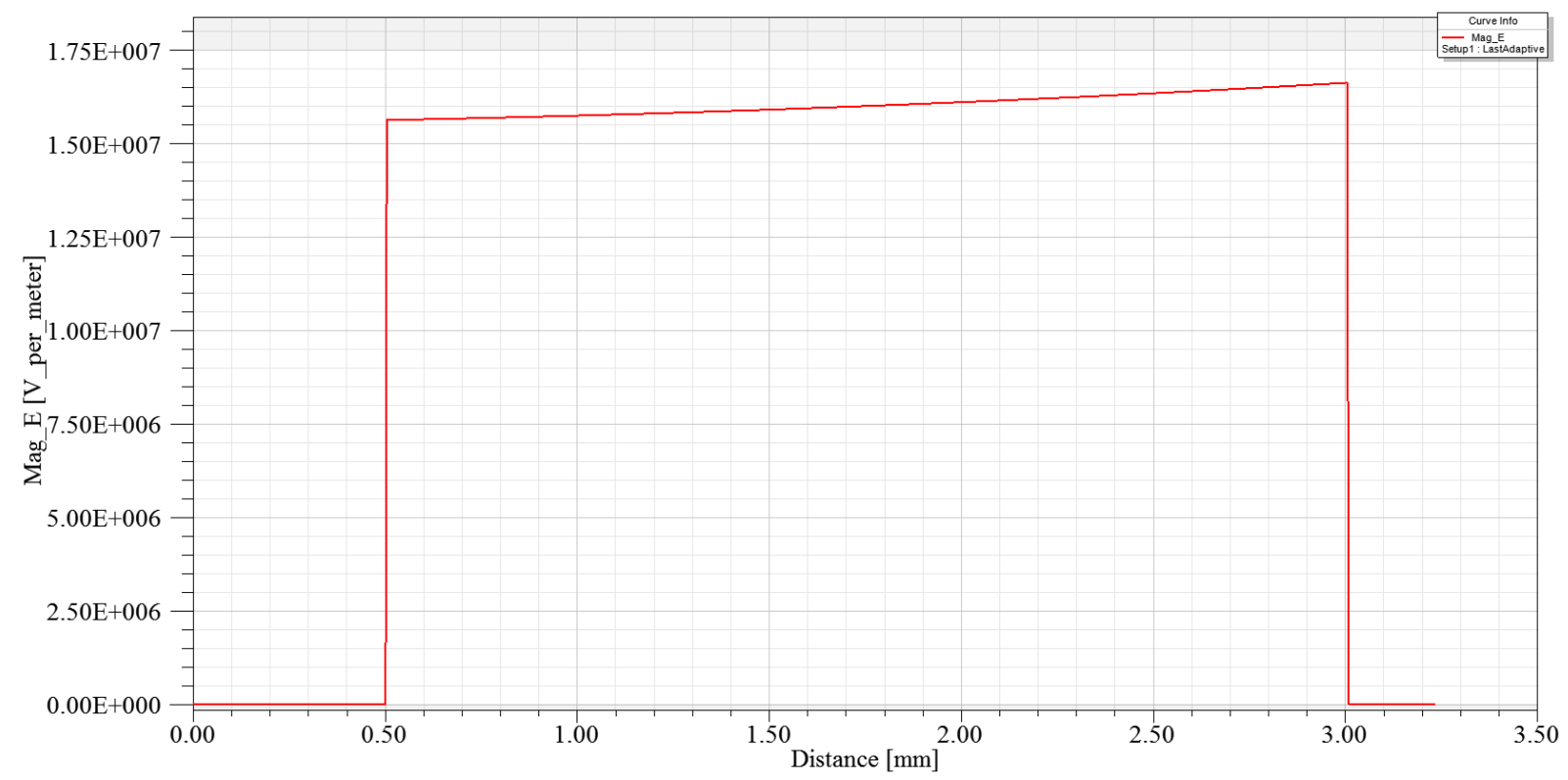

Fig. 2 - Calculated graph of the field strength along the axis of the system without particles.

Contamination of transformer oil is also associated with the formation of metal-containing colloidal particles during operation as a result of the interaction of the oil with the windings, tank, core and other structural parts of the transformer.

Particles of iron, copper and graphite (carbon) can have a different shape, including angular. The presence of sharp corners and edges will increase the degree of inhomogeneity of the field. Conducting mechanical particles were represented as a sphere with a change in diameter from 20 to 400 microns, which corresponds to the classes of liquid purity according to [13]. In this case, the highest electric field strength is observed in the gap between the electrodes. Therefore, the appearance of conductive particles in transformer oil sharply reduces its electrical strength. 
a)

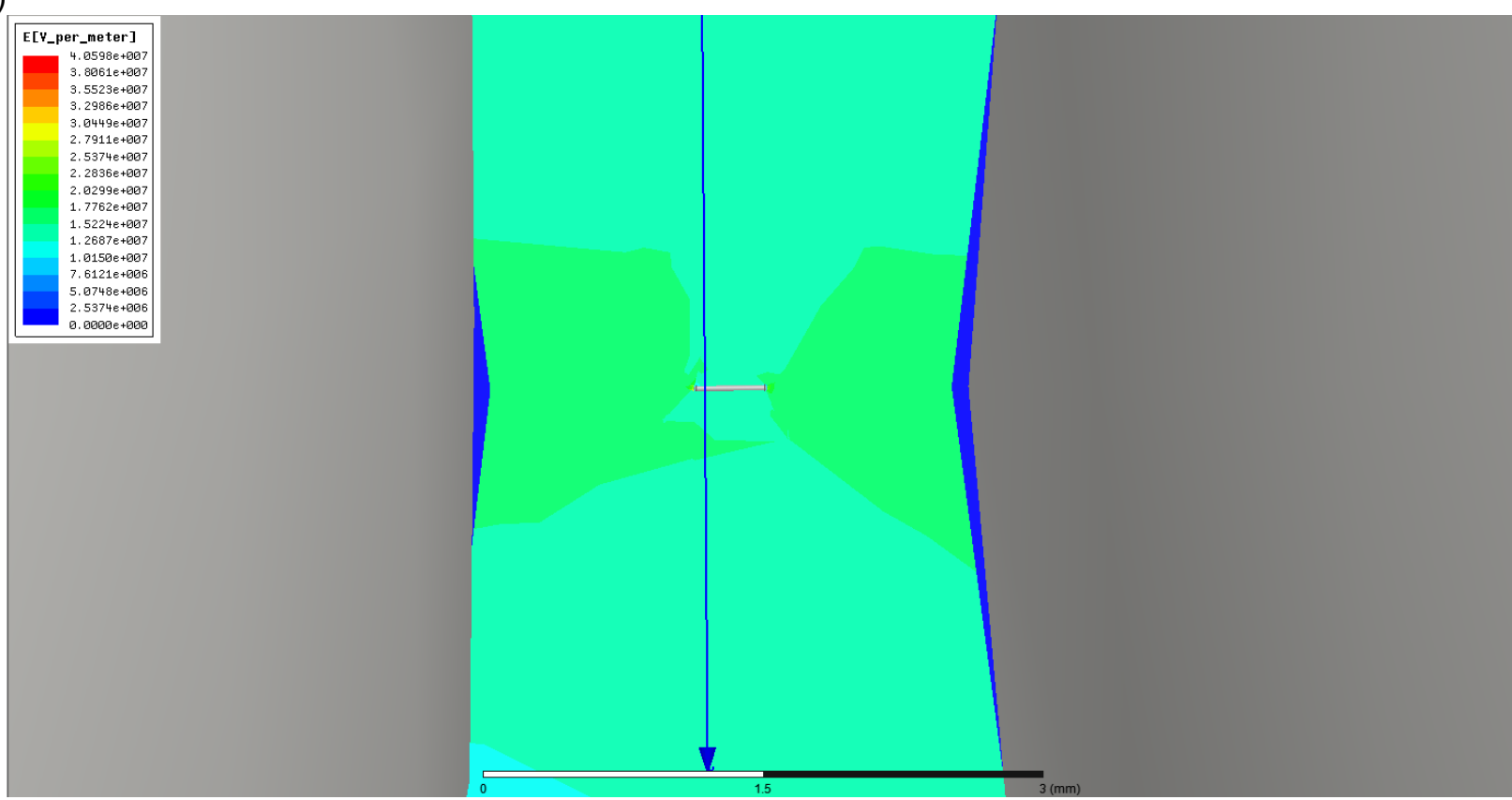

б)

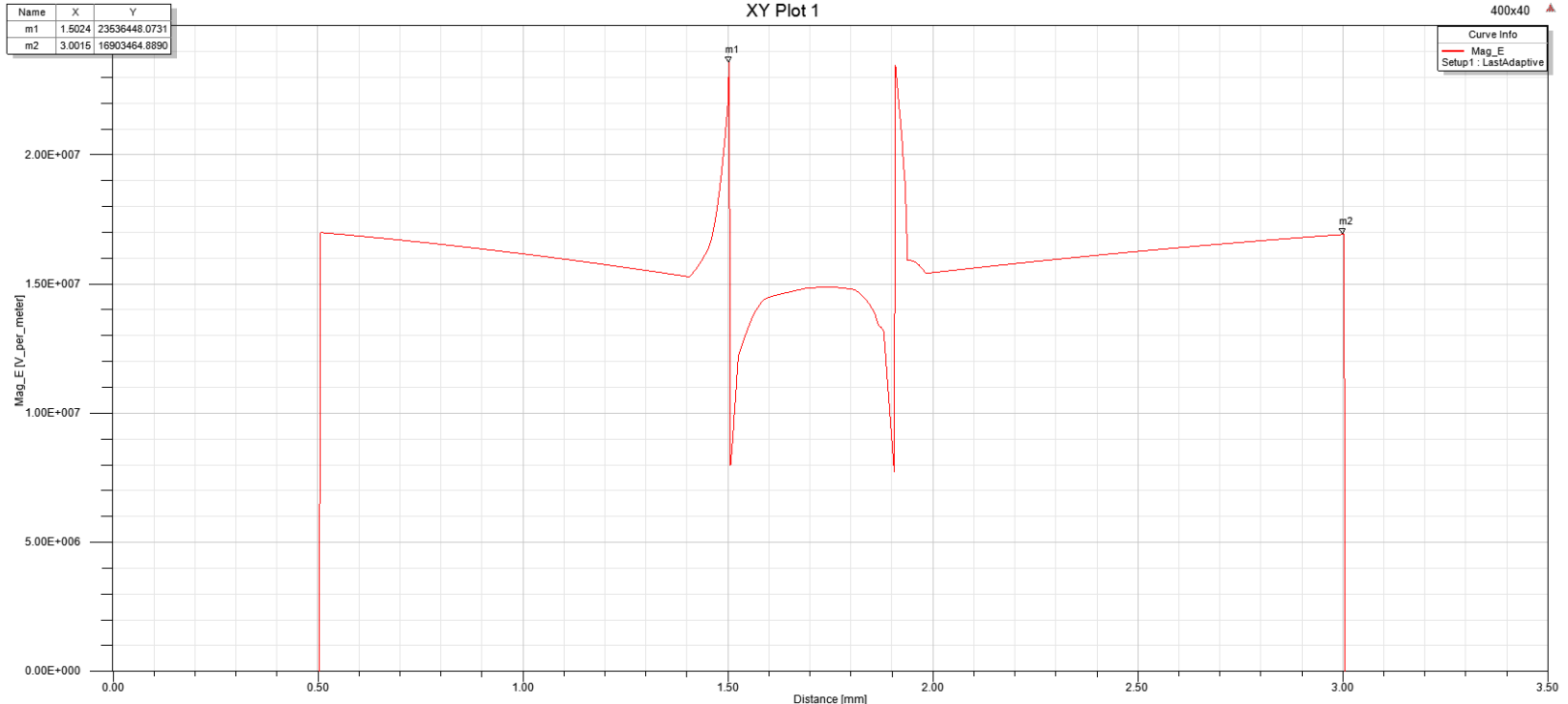

Fig. 3-an Example of an electric field pattern (a) and a graph of changes in the field strength in the presence of a wet fiber of 400 microns (b) obtained in the ANSYS Maxwell system

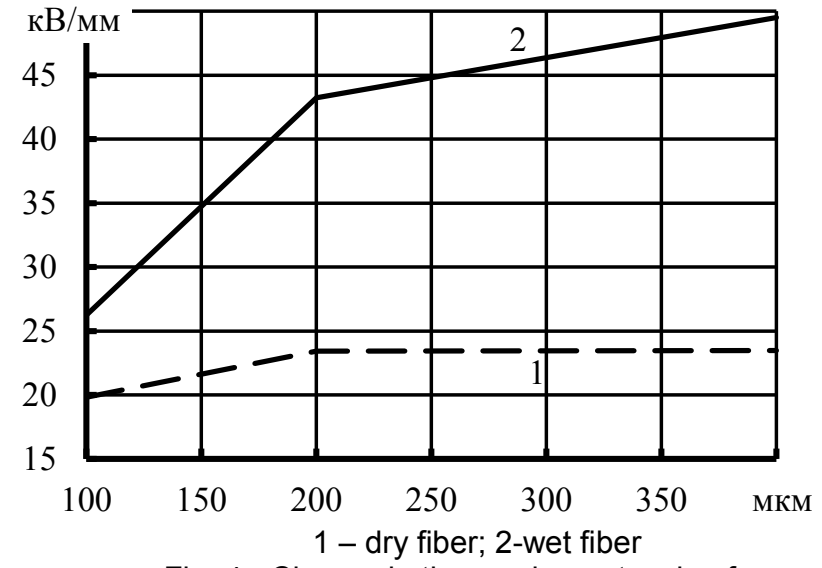

Fig. 4 - Change in the maximum tension from the length of the fibers

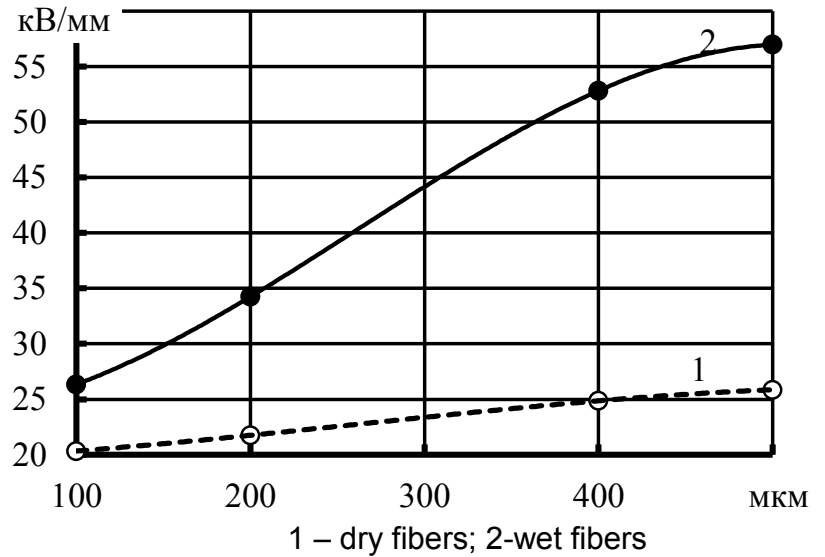

Fig. 5 - Change in the maximum tension between the bridge fibers from the length of the fibers

\footnotetext{
* Corresponding author: o.c.melnikova@mail.ru
} 


\section{Conclusions}

From the results obtained, it follows that dry fibers have a weak effect on the electrical strength of transformer oil. However, wetting the fibers leads to a sharp increase in the electric field strength at the electrodes and a decrease in the electrical strength of the insulation of power transformers. The strongest influence is exerted by moistened fibers with a length of more than 200 microns. Therefore, to reduce risks of failures of power transformers in operation in determining the breakdown voltage of transformer oil in standard arrester must consider not only the normative value of the average breakdown voltage, but also the coefficient of variation of the average value of oil breakdown voltage, which in the EP "Volume and norms of electrical equipment testing" is not reflected. Once again, it should be noted that the breakdown mechanism of transformer oil is statistical in nature, and if the coefficient of variation has sufficient values, this indicates the presence of large mechanical impurities in the oil, namely cellulose fibers.

If the transformer oil contains even a small number of conducting particles, the highest electric field strength is observed in the gap between the electrodes. To ensure a given level of electrical strength of the transformer oil, it is necessary to reduce the content of fibers in the oil longer than 200 microns and the presence of conductive particles by increasing the standard indicators of the liquid purity classes from the number of pollutant particles used in the equipment. Since moistened fibers have the greatest impact on reducing the electrical strength of oil-barrier insulation, it is necessary to control the moisture content of solid insulation and transformer oil in operation.

\section{References}

1. A.V. Mayorov, M.Y Lvov, Y.N. Lvov, V. B. Komarov, B. G. Ershov Forecasting the service life of power transformers and autotransformers of electric networks. Energetik, 11, 17-20 (2018).

2. B. A. Alekseev Large power transformers. Operational reliability, condition monitoring, and performance evaluation. Energy abroad: ADJ. to the journal. Energetik, 2, 3-56 (2008).

3. M. Y. Lvov, Y. N. Lvov, A.V. Cherezov Development of system of normative-technical documentation to ensure operational reliability of power transformers and autotransformers $110 \mathrm{kV}$ and above. Power station, 11, 54-59 (2013).

4. M. Y. Lvov, Y. N.Lvov, V. B. Komarov, S. A. Kalugin, Y. A. Mitkin, V. P. Vdovina Methodological aspects of the development of partial discharges and insulation monitoring of power transformers in operation. Energetic, 9, 16-20. (2017).

5. G. S. Kuchinsky, V. E. Kiesewetter, J. S. Pintal Insulation of high-voltage: textbook for universities. Energoatomizdat, 368 (1987)

6. G. S. Kuchinsky Partial discharges in high-voltage designs. Energy, 224 p. (1979)

7. B.A. Alekseev, F.L. Kogan, L.G. Mamikoniants RD 34.45-51.300-97. The scope and norms of testing electric equipment. Ed. 6th, with ed. and add. NC ENAS (2004).
8. GOST 6581-75 (ST COMECON 3166-81). Electrical insulation materials are liquid. Methods of electrical tests. IPK publishing house of standards (1998).

9. ASTM D1816-67 (1971, USA). Method for determining the breakdown voltage of oil electrical insulation oils using VDE-electrodes. Collection of US standards for testing electrical insulation materials, translated from English by prof. N. V. Alexandrov. Energiya (1979).

10. O. S. Melnikova Selection and calculation of statistical characteristics of electrical strength of oil channels of the main insulation of transformers to improve the efficiency of its diagnostics. Vestnik IGEU, 3, 38-44. (2014).

11. Y.A. Mitkin, O. S. Melnikova Diagnostic statistical characteristics of oil breakdown voltages of active power transformers $110 \mathrm{kV}$. Vestnik IGEU, 3, 40-46. (2016).

12. G. I. Skanavi Physics of dielectrics (region of strong fields). GIFML, 907 (1958).

13. GOST 17216-2001. The purity of industrial. Liquid purity classes. The interstate Council for standardization, Metrology and certification. (2001).

14. O. S. Melnikova Influence of the size distribution of impurity particles on the electrical strength of transformer oil. Vestnik IGEU, 6, 41-49 (2019). 